\title{
Verifikasi Metode Pengujian Coliform dalam Sampel Air Mineral
}

\section{Verification of Coliform Testing Methods in Mineral Water Samples}

\author{
Kurnia Rahmayati Rifai \\ Balai Riset dan Standardisasi Industri Surabaya \\ Kementerian Perindustrian \\ Surabaya, Indonesia \\ nia.yuliarta@gmail.com
}

\author{
Anissa \\ Balai Riset dan Standardisasi Industri Surabaya \\ Kementerian Perindustrian \\ Surabaya, Indonesia \\ indahnyahijab@gmail.com
}

\begin{abstract}
Abstrak - Verifikasi metode pengujian Coliform dalam Air Mineral secara penyaringan membran yang mengacu pada SNI 3554 : 2015 Cara Uji Air Minum Dalam Kemasan telah dilakukan di Laboratorium Uji Baristand Industri Surabaya dan didapatkan nilai Presisi pada sampel dengan penambahan cemaran sebesar 10 koloni/ml sebesar 0.000 , sampel dengan penambahan cemaran sebesar $100 \mathrm{koloni} / \mathrm{ml}$ sebesar 0.000 , sampel dengan penambahan cemaran sebesar $500 \mathrm{koloni} / \mathrm{ml}$ sebesar 0.0699, sampel dengan penambahan cemaran sebesar $700 \mathrm{koloni} / \mathrm{ml}$ sebesar 0.0467 , sampel dengan penambahan cemaran sebesar $1000 \mathrm{koloni} / \mathrm{ml}$ sebesar 0.000 , Nilai Recovery pada sampel dengan penambahan cemaran sebesar $10 \mathrm{koloni} / \mathrm{ml}$ sebesar $\mathbf{8 5 . 0 3 \%}$, sampel dengan penambahan cemaran sebesar $100 \mathrm{koloni} / \mathrm{ml}$ sebesar $\mathbf{1 0 0 . 8 5 \%}$, sampel dengan penambahan cemaran sebesar $500 \mathrm{koloni} / \mathrm{ml}$ sebesar $99.22 \%$, sampel dengan penambahan cemaran sebesar $700 \mathrm{koloni} / \mathrm{ml}$ sebesar $99.41 \%$, sampel dengan penambahan cemaran sebesar $1000 \mathrm{koloni} / \mathrm{ml}$ sebesar $104.80 \%$. Nilai linearitas sebesar 0.994. Hasil verifikasi tersebut telah memenuhi syarat keberterimaan sehingga metode tersebut dapat diterapkan di Labaoratorium Uji Baristand Industri Surabaya
\end{abstract}

Kata kunci - air mineral; Verifikasi metode; Coliform

\begin{abstract}
Verification of Coliform testing method in Mineral Water by membrane filter that refers to SNI 3554: 2015 Cara Uji Air Minum Dalam Kemasan has been carried out at the Testing Laboratory of Baristand Industri Surabaya and obtained a Precision value on the sample with the addition of contamination of $10 \mathrm{cfu} / \mathrm{ml}$ of 0,000 , samples with addition of contamination by $100 \mathrm{cfu} / \mathrm{ml}$ by 0,000 , samples with addition of contamination by $500 \mathrm{cfu} / \mathrm{ml}$ by 0.0699 , samples with addition of contamination by $700 \mathrm{cfu} / \mathrm{ml}$ by 0.0467 , samples with addition of contamination by $1000 \mathrm{cfu} / \mathrm{ml}$ by 0,000, Recovery Value in samples with the addition of contaminants by $10 \mathrm{cfu}$ / $\mathrm{ml}$ by $85.03 \%$, samples with the addition of contamination by 100 cfu / $\mathrm{ml}$ by $100.85 \%$, samples with the addition of contamination by $500 \mathrm{cfu}$ / the $\mathrm{ml}$ by $99.22 \%$, samples with the addition of contamination by 700 $c f u / \mathrm{ml}$ by $99.41 \%$, samples with the addition of contamination of 1000 cfu / $\mathrm{ml}$ by $104.80 \%$. The value of linearity is 0.994. The verification results have met acceptance requirements so that the method can be applied in the Baristand Industri Surabaya Test Laboratory
\end{abstract}

Keywords-Mineral water; Method verification; Coliform

\section{PENDAHULUAN}

Menurut Peraturan Menteri Kesehatan RI No. 492/MENKES/PER/IV/2010, air minum adalah air yang melalui proses pengolahan atau tanpa proses pengolahan yang memenuhi syarat kesehatan dapat langsung diminum, tidak berasa, tidak berbau, tidak berwarna, bebas dari cemaran kimia, radioaktif dan mikrobiologi. Persyaratan kimia dan radioaktif yaitu air minum yang dikonsumsi tidak boleh mengandung bahan-bahan kimia dan radioaktif melebihi dari ambang batas yang ditentukan. Persyaratan mikrobiologi yaitu air yang dikonsumsi bebas dari kontaminasi kuman Escherichia coli dan Coliform, keberadaan bakteri Escherichia coli dan Coliform merupakan sebagai indikator pencemaran tinja dalam air. Standar kandungan Escherichia coli dan Coliform dalam air minum 0/100 ml sampel. Adanya mikroorganisme dalam air menjadi salah satu parameter mikrobiologi yang dapat menentukan persyaratan kualitas air.

Dalam SNI 3553:2015 Air mineral disebutkan bahwa Air Minum dalam Kemasan adalah air yang telah diproses, tanpa bahan pangan lainnya, dan tanpa bahan tambahan pangan, dikemas, serta aman untuk diminum.

Air Mineral adalah air minum dalam kemasan yang mengandung mineral dalam jumlah tertentu tanpa menambahakan mineral, dengan atau tanpa penambahan oksigen $\left(\mathrm{O}_{2}\right)$ atau karbondioksida $\left(\mathrm{CO}_{2}\right)$ [19].

Bahan baku utama yang digunakan adalah air yang diambil dari sumber yang terjamin kualitasnya. Air bahan baku untuk industri air minum dalam kemasan harus lolos uji Air Baku sesuai Peraturan Menteri Kesehatan RI No. 32 Tahun 2017 tentang Standar Baku Mutu Kesehatan Lingkungan dan Persyaratan Kesehatan Air untuk Keperluan Higiene Sanitasi, Kolam Renang, Solus Per Aqua dan Pemandian Umum.

Dalam SNI 3553: 2015 pengujian terhadap mutu air mineral terbagi menjadi 3 bagian, yaitu :

a. Pengujian fisika, meliputi bau, rasa, warna, $\mathrm{pH}$, kekeruhan dan padatan terlarut

b. Pengujian kimia, meliputi pengujian logam-logam mineral dan logam berat 


\section{JURNAL TEKNOLOGI PROSES DAN INOVASI INDUSTRI, VOL. 4, NO. 2, NOVEMBER 2019}

c. Pengujian biologi, meliputi uji cemaran Angka Lempeng Total, Coliform dan Pseudomonas aeruginosa

Hasil pengujian cemaran mikrobiologi merupakan salah satu penentu kualitas dari produk air mineral.

Coliform didefinisikan sebagai kelompok bakteri Gramnegatif, berbentuk batang, oksidase-negatif, aerob sampai anaerob fakultatif, tidak membentuk spora, mampu tumbuh secara aerobik pada media agar yang mengandung garam empedu, dan mampu memfermentasikan laktosa dengan membentuk gas dan asam dalam waktu 48 jam pada suhu $37^{\circ} \mathrm{C}$. Jumlah coliform yang diperoleh dari inkubasi pada suhu $37^{\circ} \mathrm{C}$ tersebut biasanya dinyatakan sebagai total coliform. Sementara faecal coliform merupakan bagian dari coliform total dan dipresentasikan oleh total bakteri coliform toleran panas yang mampu tumbuh pada suhu 44,5 $\pm 0,2^{\circ} \mathrm{C}$ dengan memfermentasikan laktosa dan memproduksi asam dan gas [5]. Golongan bakteri Coliform adalah Citrobacter, Enterobacter, Escherichia coli, dan Klabsiella [2]. Bakteri Coliform adalah golongan bakteri intestinal yaitu hidup di dalam saluran pencernaan manusia [14]. Penggolongan bakteri Coliform dan sifat-sifatnya, dibagi menjadi dua yaitu Coliform fekal diantaranya bakteri Escherichia coli berasal dari tinja manusia. Coliform non fekal diantaranya Aerobacter dan Klabsiella yang bukan berasal dari tinja manusia, melainkan berasal dari hewan/tanaman yang sudah mati [13]. Escherichia coli termasuk famili Enterobacteriaceae, berbentuk batang, gram negatif, tidak membentuk spora, hidup dalam suasana fakultatif anaerob, oksidase negatif, katalase positif. Escherichia coli mempunyai enzim $\beta$ galaktosidase \& $\beta$ galaktoside permiase, untuk memfermentasi macam-macam karbohidrat, menghasilkan asam dan gas [4]. Bakteri Coliform termasuk flora normal usus besar manusia dan hewan berdarah panas, tidak berbahaya namun ada beberapa strain yang patogen pada manusia maupun hewan. Escherichia coli dapat dijumpai pada air, makanan, tanah yang terkontaminasi oleh tinja. Adanya bakteri Coliform dalam air menunjukan air terkontaminasi oleh tinja bersifat patogen di dalam usus, sehingga tidak layak untuk dikonsumsi [12].

Media CCA, digunakan untuk mengamati bakteri coliform dan Escherichia coli. Media CCA adalah media yang sangat selektif untuk uji analisa Coliform. Komposisi dari media CCA yaitu, pepton, sodium chlorid, sodium dihidrogen posphat, disodium hidrogen posphat, sodium piruvat, sorbitol, tergitol, Chromogenic mixture (Salmon-GAL dan X-Glucoronid). Tergitol akan menghambat pertumbuhan bakteri gram positif dan sebagian bakteri Gram negatif tetapi tidak mempengaruhi pertumbuhan bakteri Coliform. Pepton, pyruvat, sorbitol, sodium dihidrogen phosphat, disodium hidrogen phospat, akan mempercepat pertumbuhan Coliform [7]. Chromogenic mixture berfungsi untuk mendeteksi total dari bakteri Coliform dan E. coli. Coliform mempunyai enzim $\beta$-galaktosidase berfungsi untuk memotong subtrat Salmon-GAL menjadi salmon (senyawa chromogenik) berwarna merah. Bakteri $E$. coli mempunyai enzim $\beta$ galaktosidase dan enzim $\beta$ - galaktosidase permise, memotong substrat X-Glucoronide menjadi X dan Glucoronide berwarna biru tua-violet. Triptofan akan mengikat reaksi indol sehingga akan meningkatkan deteksi E. coli [1].

Verifikasi metode adalah suatu kegiatan yang dilakukan oleh laboratorium dalam rangka memastikan bahwa suatu metode yang diacu dapat memberikan hasil pengujian yang akurat seperti yang diharapkan oleh pembuat metode. Dalam SNI ISO/IEC 17025:2017 disebutkan bahwa laboratorium harus menggunakan metode dan prosedur yang sesuai untuk semua aktivitas laboratorium dan, jika sesuai, untuk evaluasi ketidakpastian pengukuran serta teknik statistik untuk analisis data. Laboratorium harus memverifikasi metode yang digunakan dan menunjukkan bahwa ia dapat menerapkan metode dengan benar sebelum mengenalkannya dengan memastikan bahwa ia dapat mencapai kinerja yang diinginkan. Rekaman verifikasi harus disimpan. Jika metode direvisi oleh penerbitnya, verifikasi harus diulang sejauh diperlukan [11]. Parameter verifikasi yang dilakukan untuk metode penyaringan membran adalah penetapan presisi, perolehan kembali (recovery) dan linearitas kurva [8]. Batas keberterimaan hasil verifikasi untuk parameter presisi adalah $<0.1$, parameter linearitas $\mathrm{R}^{2}>0.95$ [8], dan parameter akurasi \% $\mathrm{R}: 85$ - 105\% [3]

\section{BAHAN DAN METODE}

\section{A. Alat}

Peralatan yang digunakan antara lain Cawan Petri Ø $90-100$ $\mathrm{mm}$, Membran filter, Filter funnel, Pompa Vakum, Pipet ukur berskala $1 \mathrm{ml}$ dan $10 \mathrm{ml}$, Inkubator $35-37{ }^{\circ} \mathrm{C} \quad{ }^{\circ} \mathrm{C}$, Colony counter, Laminer Air Flow seperti pada gambar 1 dibawah ini.

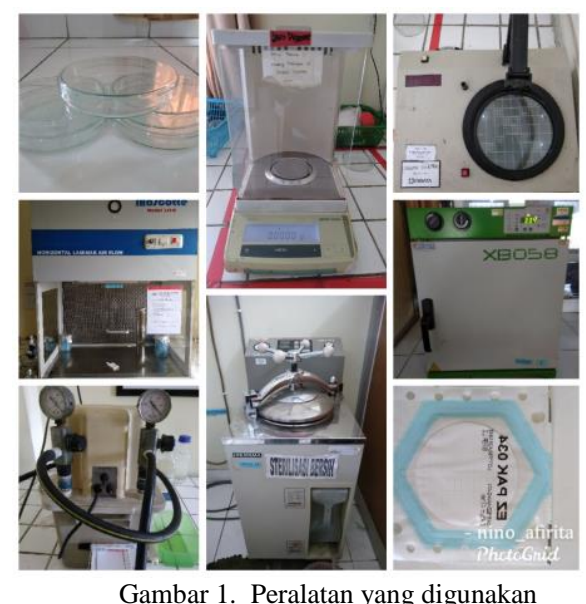

\section{B. Media dan Bahan Uji}

Bahan yang digunakan seperti pada gambar 2 dan 3, antara lain Air mineral dalam kemasan botol, Coliform Chromocult Agar ( CCA ), Oksidase strip. Pepton Dilution Fluid (PDF) Plate Count Agar (PCA), Nutrien agar (NA), Brain Heart Infusion Broth (BHIB). 


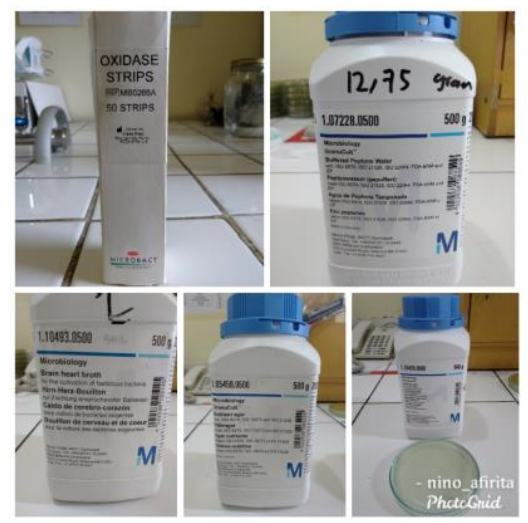

Gambar 2. Media yang digunakan

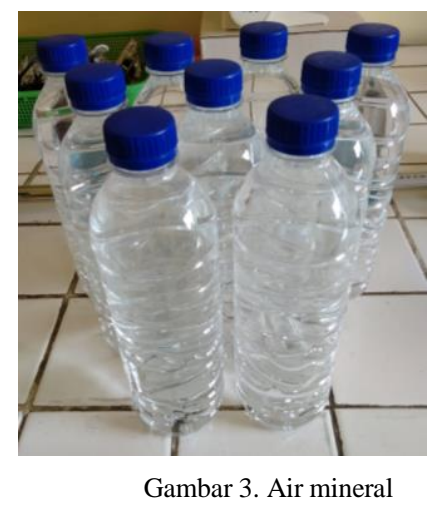

Mikroba yang digunakan adalah mikroba Baku Escherichia coli ATCC 25922, seperti pada gambar dibawah 4 dibawah ini.

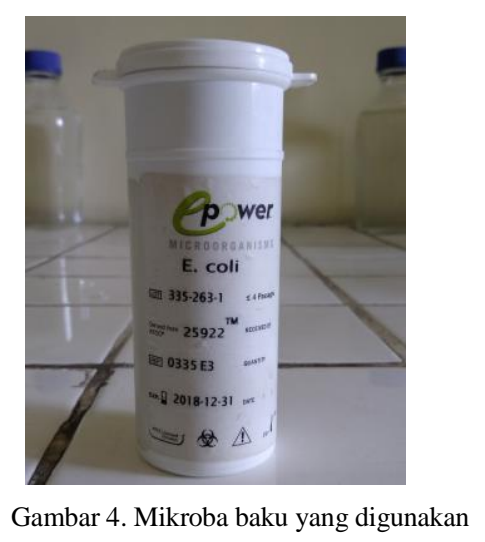

\section{Metodologi}

\section{1) Pembuatan Inokulum.}

a. Bakteri mesofil aerob yang sesuai (Escherichia coli) diinokulasikan dalam NA miring, diinkubasi pada 35 $-37^{\circ} \mathrm{C}$ selama 24 jam. b. Biakan dalam tabung reaksi dibilas dengan $5 \mathrm{ml}$ BHIB, inkubasikan pada suhu $35-37{ }^{\circ} \mathrm{C}$ selama 24 jam, susupensi tersebut digunakan sebagai suspensi induk bakteri.

c. Dari suspensi induk dilakukan pengenceran hingga diperoleh inokulum dengan kepekatan atau konsentrasi $10-100 \mathrm{cfu} / \mathrm{ml}$ dengan cara lempeng dan inokulum tersebut digunakan untuk menspike sampel dan kontrol positif.

d. Suspensi bakteri mesofil aerob dapat disimpan dalam lemari pendingin bersuhu $4{ }^{\circ} \mathrm{C}$ selama 7 hari.

e. Ditetapkan dengan cara sebagai berikut:

Biakan bakteri Escherichia coli pada NA miring diinokulasikan kedalam $10 \mathrm{ml}$ BHIB, diinkubasi pada suhu $35-37^{0} \mathrm{C}$ selama 24 jam suspensi tersebut digunakan sebagai suspensi bakteri Escherichia coli.

f. Dipipet $1 \mathrm{ml}$ suspensi biakan ke dalam $9 \mathrm{ml}$ PDF .

g. Dari suspensi pengenceran $10^{-1}$ dipipet $1 \mathrm{ml} \mathrm{ke}$ dalam tabung PDF hingga pengenceran $10^{-10}$

h. Dipipet $1 \mathrm{ml}$ dari setiap pengenceran ke dalam cawan petri dan dibuat duplo.

TABLE I. Hasil PembacaAn ALT Escherichia Coli ATCC 25922

\begin{tabular}{|c|c|c|c|c|}
\hline $\begin{array}{c}\text { Pengenceran } \\
\text { Mikroba Uji }\end{array}$ & $10^{-7}$ & $10^{-8}$ & $10^{-9}$ & $10^{-10}$ \\
\hline $\begin{array}{c}\text { Inkubasi } 35-37^{0} \\
\text { C, }\end{array}$ & 211 & 31 & 3 & 0 \\
24 jam & 206 & 27 & 1 & 0 \\
\hline $\begin{array}{c}\text { Inkubasi 35 -37 } \\
\text { C, }\end{array}$ & 222 & 35 & 3 & 0 \\
48 jam & 218 & 27 & 2 & 0 \\
\hline
\end{tabular}

Hasil ALT tersebut di atas adalah :

$$
\begin{array}{lc}
\text { ALT } & =\frac{222+218}{2} \\
\text { ALT } & =220.10^{7} \\
\text { ALT } & =22.10^{8} \mathrm{kol} / \mathrm{ml}
\end{array}
$$

Cara penambahan Inokulum bakteri sebagai cemaran ( 100 koloni/ml )

Dibuat pengenceran dari stock bakteri untuk cemaran.

(Suspensi bakteri pada medium BHIB 24 jam yang telah diketahui kepekatan-nya, yaitu $22.10^{8}$ $\mathrm{kol} / \mathrm{ml}$ ) 


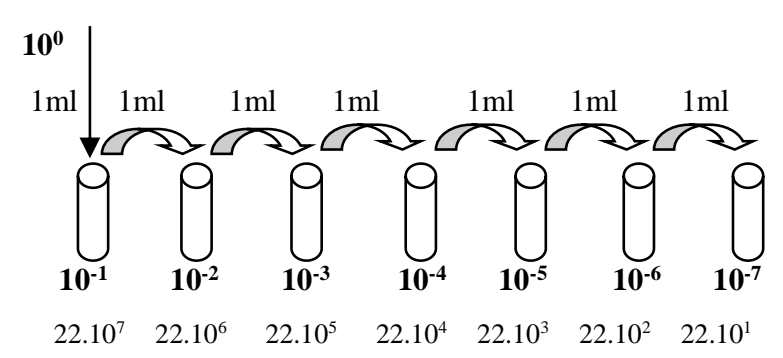

2) Perlakuan Sampel. a) Sampel

Sampel tanpa tambahan apapun (konsentrasi 0 koloni/ml).

- $250 \mathrm{~mL}$ sampel air minum (mineral/demineral) disaring menggunakan membrane filter dan dibilas dengan akuades steril

- Tempatkan membrane filter di atas media CCA menggunakan pinset steril

- Diinkubasikan pada suhu $(36 \pm 2)^{\circ} \mathrm{C}$ selama $(21 \pm 3)$ jam

- Jumlah koloni yang tumbuh diamati dan dihitung. Koloni coliform berwarna merah muda sampai merah tua, koloni E coli berwarna biru sampai ungu.

- Koloni coliform dikonfirmasi menggunakan oksidase strip. Bila koloni berwarna biru, berarti negatif

\section{b) Sampel Positif.}

Sampel ditambah inokulum suspensi bakteri dengan 5 tingkat konsentrasi $( \pm 10,100,500,700,1000 \mathrm{koloni} / \mathrm{ml} \mathrm{sampel})$.

- $250 \mathrm{~mL}$ sampel Air Mineral

- Ditambahkan suspensi bakteri :

1. Untuk 10 koloni :

Untuk $25 \mathrm{~mL}$ sampel dengan konsentrasi inokulum 10 koloni/ml sampel diperlukan 250 koloni.

$$
\frac{250}{22 \times 10^{3}} \times 1 m L=1 m L \text { dari seri10 } 0^{-7}
$$

2. Untuk 100 koloni :

Untuk $25 \mathrm{~mL}$ sampel dengan konsentrasi inokulum 100 koloni/ml sampel diperlukan 2500 koloni.

$$
\frac{2500}{22 \times 10^{8}} \times 1 \mathrm{~mL}=1 \mathrm{~mL} \text { dari seri } 10^{-6}
$$

3. Untuk 500 koloni :

Untuk $25 \mathrm{~mL}$ sampel dengan konsentrasi inokulum 500 koloni/ml sampel diperlukan 12.500 koloni.

$$
\frac{12500}{22 \times 10^{8}} \times 1 \mathrm{~mL}=5,6 \mathrm{~mL} \text { dari seri } 10^{-6}
$$

4. Untuk 700 koloni :

Untuk $25 \mathrm{~mL}$ sampel dengan konsentrasi inokulum 700 koloni/ml sampel diperlukan 17.500 koloni.

$$
\frac{17500}{22 \times 10^{8}} \times 1 m L=8 m L \text { dari seri } 10^{-4}
$$

\section{Untuk $1000 \mathrm{cfu}$ :}

Untuk $25 \mathrm{~mL}$ sampel dengan konsentrasi inokulum 1000 koloni/ml sampel diperlukan 25.000 koloni.

$$
\frac{25000}{22 \times 10^{8}} \times 1 \mathrm{~mL}=1 \mathrm{~mL} \text { dari seri } 10^{-5}
$$

- Kemudian dilakukan sesuai prosedur coliform

Kelompok sampel dan sampel positif dikerjakan sebanyak $5 \mathrm{x}$ ulangan, sedangkan kelompok kontrol positif cukup dikerjakan dua kali ulangan

- disaring menggunakan membrane filter dan dibilas dengan akuades steril

- Tempatkan membrane filter di atas media CCA menggunakan pinset steril

- Diinkubasikan pada suhu $(36 \pm 2)^{\circ} \mathrm{C}$ selama $(21 \pm 3)$ jam

- Jumlah koloni yang tumbuh diamati dan dihitung. Koloni coliform berwarna merah muda sampai merah tua, koloni E coli berwarna biru sampai ungu

- Koloni coliform dikonfirmasi menggunakan pereaksi oksidase. Bila koloni berwarna biru, berarti negative

\section{c) Kontrol Positif}

Akuades steril ditambah inokulum suspensi bakteri dengan 5 tingkat konsentrasi $( \pm 10,100,500,700,1000$ koloni $/ \mathrm{mL}$ pengencer).

Ditambahkan suspensi bakteri dengan jumlah yang sama, ditambahkan pada cemaran sampel positif dilakukan pengujian dua kali ulangan

\section{3) Linieritas}

Linieritas dilihat dari hasil pengujian coliform dari kelompok kontrol positif dan kelompok sampel dengan cemaran mikroba. Derajat linearitas kurvanya harus lebih besar dari 0.95 . 


$$
\mathrm{R}^{2}>0.95
$$

4) Presisi

Presisi adalah tingkat kesesuaian antara hasil tes individu ketika suatu metode diterapkan berulang kali ke beberapa sampel dari sampel yang homogen. Ketepatan metode ini biasanya dinyatakan sebagai relatif standar deviasi (koefisien variasi) dari serangkaian pengukuran [8]. Presisi diukur dengan menghitung Relative Standard Deviation atau simpangan baku relatif (RSD) dari ulangan sampel. Rumus perhitungan RSD adalah sebagai berikut :

$$
R S D=\frac{S D}{X r} \times 100
$$

Dimana :

$\mathrm{SD}=$ simpangan baku log hasil uji

$\mathrm{Xr}=$ rata-rata log hasil uji

Syarat keberterimaannya adalah RSD harus lebih kecil dari 0,1

$$
\text { RSD }<0.1
$$

\section{5) Perolehan kembali (Recovery, \%R)}

Perolehan kembali adalah tingkat kesesuaian antara jumlah mikroorganisme yang diperoleh antara control positif dan sampel yang ditambah cemaran menggunakan metode referensi yang dapat diterima [8]. Recovery diukur dengan membandingkan rata-rata log hasil kelompok sampel ditambah cemaran dengan rata-rata log hasil kelompok control positif. Recovery dapat digunakan untuk mengetahui tingkat akurasi hasil pengujian. Rumus perhitungannya adalah sebagai berikut :

$$
\% R=\frac{X r_{\text {logsampel }}}{X r_{\text {logkontrolpositi }}} \times 100
$$

Dimana :

$\% \mathrm{R}=$ perolehan kembali

$\mathrm{Xr}=$ rata-rata $\log$ hasil uji

Syarat keberterimaannya harus berada dalam batas $85 \%$ sampai $105 \%$

$$
85 \%<\% \mathrm{R}<105 \%
$$

\section{HASIL DAN PEMBAHASAN}

\section{A. Standar Mutu Air Mineral}

Standar Nasional Indonesia untuk Air Mineral yang ditetapkan oleh Badan Standardisasi Nasional pada tahun 2015

dapat dilihat pada Tabel II. Ditinjau dari syarat mutu yang tercantum dalam SNI Air Mineral, tampak bahwa syarat mutu yang ditetapkan sudah cukup ketat. Hal ini dikarenakan produk air mineral adalah produk yang dikonsumsi langsung tanpa perlu dimasak terlebih dahulu.

TABLE II. Syarat Mutu CEMARAN Mikroba DAlam Air Mineral SESUAI SNI 3553:2015

\begin{tabular}{|c|c|c|c|}
\hline No & KriteriaUji & Satuan & Persyaratan \\
\hline 1 & CemaranMikroba & & \\
\hline 1.1 & $\begin{array}{r}\text { Angka Lempeng Total } \\
\text { Awal **) }\end{array}$ & Koloni $/ \mathrm{mL}$ & Maks. $1,0 \times 10^{2}$ \\
\hline 1.2 & $\begin{array}{r}\text { Angka Lempeng Total } \\
\text { Akhir } * * *)\end{array}$ & Koloni $/ \mathrm{mL}$ & Maks. 1,0 x $10^{5}$ \\
\hline 1.3 & Coliform & koloni $/ 250 \mathrm{~mL}$ & TTD \\
\hline 1.4 & $\begin{array}{r}\text { Pseudomonas } \\
\text { aeruginosa }\end{array}$ & koloni $/ 250 \mathrm{~mL}$ & TTD \\
\hline $\begin{array}{l}\text { Catatan : } \\
\text { **) Di Pabrik } \\
\text { ***) Di Pasaran } \\
\text { TTD : Tidakterdeteksi }\end{array}$ & \\
\hline
\end{tabular}

\section{B. Hasil Verifikasi Metode Cemaran Coliform}

Hasil pertumbuhan bakteri setelah diinkubasikan selama $21 \pm 3$ jam pada suhu $36 \pm 2^{\circ} \mathrm{C}$ ditampilkan dalam tabel berikut :

TABLE III. Hasil Jumlah COLIFORM AIR Mineral DAN Kontrol PositiF

\begin{tabular}{|c|c|c|c|c|c|c|c|c|c|c|c|}
\cline { 2 - 12 } \multicolumn{1}{c|}{ Ulangan } & S- & SC 10 & C10 & SC100 & C100 & SC500 & C500 & SC700 & C700 & SC1000 & C1000 \\
\hline $\mathbf{1}$ & $\mathbf{0}$ & 12.5 & $\mathbf{1 5}$ & 122.5 & $\mathbf{1 2 0}$ & 520 & $\mathbf{5 4 0}$ & 725 & $\mathbf{7 5 5}$ & 1400 & $\mathbf{1 1 7 5}$ \\
\hline $\mathbf{2}$ & $\mathbf{0}$ & 12.5 & $\mathbf{1 5}$ & 122.5 & $\mathbf{1 2 0}$ & 517.5 & $\mathbf{5 4 0}$ & 732.5 & $\mathbf{7 5 5}$ & 1400 & $\mathbf{1 1 7 5}$ \\
\hline $\mathbf{3}$ & $\mathbf{0}$ & 12.5 & & 122.5 & & 520 & & 732.5 & & 1400 & \\
\hline $\mathbf{4}$ & $\mathbf{0}$ & 12.5 & & 122.5 & & 520 & & 732.5 & & 1450 & \\
\hline $\mathbf{5}$ & $\mathbf{0}$ & 12.5 & & 122.5 & & 520 & & 732.5 & & 1400 & \\
\hline
\end{tabular}

Tabel III adalah hasil pengujian Coliform pada 3 kelompok perlakuan yaitu kelompok sampel tanpa cemaran, kelompok sampel positif atau sampel yang ditambah cemaran bakteri dengan konsentrasi tertentu dan kelompok control positif atau bakteri dengan konsentrasi tertentu yang dibiakkan dalam akuades steril. Untuk kelompok sampel tanpa cemaran dan kelompok sampel positif, pengujian dilakukan dengan 5 (lima) kali ulangan. Sedangkan kelompok control positif dilakukan 


\section{JURNAL TEKNOLOGI PROSES DAN INOVASI INDUSTRI, VOL. 4, NO. 2, NOVEMBER 2019}

pengujian dengan tertentu yang dibiakkan dalam akuades steril. Untuk kelompok sampel tanpa cemaran dan kelompok sampel positif, pengujian dilakukan dengan 5 (lima) kali ulangan.
Sedangkan kelompok control positif dilakukan pengujian dengan 2 (dua) kali ulangan.

TABle IV. Pengolahan Data Coliform Pada Air Mineral

\begin{tabular}{|c|c|c|c|c|c|c|c|c|c|c|c|}
\hline \multirow{2}{*}{ Kondisi } & \multirow{2}{*}{$\begin{array}{l}\text { Hasil } \\
\text { ALT }\end{array}$} & \multirow{2}{*}{$\begin{array}{l}\text { Log } \\
\text { ALT }\end{array}$} & & & \multicolumn{2}{|c|}{ Rata-rata } & \multicolumn{2}{|c|}{ Stand.Dev } & \multirow{2}{*}{$\% \mathbf{R}$} & \multicolumn{2}{|c|}{ Presisi (RSD \%) } \\
\hline & & & & & Spl & $\overline{\text { Ctrl }}$ & Spl & Ctrl & & Spl & Ctrl \\
\hline S1 & 0 & 0 & 0 & 0 & 0 & 0 & 0 & 0 & & & \\
\hline S2 & 0 & 0 & 0 & 0 & & & & & & & \\
\hline S3 & 0 & 0 & 0 & 0 & & & & & & & \\
\hline S4 & 0 & 0 & 0 & 0 & & & & & & & \\
\hline S5 & 0 & 0 & 0 & 0 & & & & & & & \\
\hline $\mathrm{S} 1+10$ & 12.5 & 1.10 & 15 & 1.18 & 1.00 & 1.18 & 0.0000 & 0.0000 & 85.03 & 0.0000 & 0.0000 \\
\hline $\mathrm{S} 2+10$ & 12.5 & 1.10 & 15 & 1.18 & & & & & & & \\
\hline S3+10 & 12.5 & 1.10 & & & & & & & & & \\
\hline $\mathrm{S} 4+10$ & 12.5 & 1.10 & & & & & & & & & \\
\hline $\mathrm{S} 5+10$ & 12.5 & 1.10 & & & & & & & & & \\
\hline$S 1+100$ & 122.5 & 2.09 & 120 & 2.08 & 2.10 & 2.08 & 0.0000 & 0.0000 & 100.85 & 0.0000 & 0.0000 \\
\hline $\mathrm{S} 2+100$ & 122.5 & 2.09 & 120 & 2.08 & & & & & & & \\
\hline S3+100 & 122.5 & 2.09 & & & & & & & & & \\
\hline S4+100 & 122.5 & 2.09 & & & & & & & & & \\
\hline S5+100 & 122.5 & 2.09 & & & & & & & & & \\
\hline $\mathrm{S} 1+500$ & 520 & 2.72 & 540 & 2.73 & 2.71 & 2.73 & 0.0019 & 0.0000 & 99.22 & 0.0699 & 0.0000 \\
\hline $\mathrm{S} 2+500$ & 517.5 & 2.71 & 540 & 2.73 & & & & & & & \\
\hline $\mathrm{S} 3+500$ & 520 & 2.72 & & & & & & & & & \\
\hline S4+500 & 520 & 2.72 & & & & & & & & & \\
\hline $\mathrm{S} 5+500$ & 520 & 2.72 & & & & & & & & & \\
\hline$S 1+700$ & 725 & 2.86 & 755 & 2.88 & 2.86 & 2.88 & 0.0013 & 0.0000 & 99.41 & 0.0467 & 0.0000 \\
\hline $\mathrm{S} 2+700$ & 732.5 & 2.86 & 755 & 2.88 & & & & & & & \\
\hline $\mathrm{S} 3+700$ & 732.5 & 2.86 & & & & & & & & & \\
\hline S4+700 & 732.5 & 2.86 & & & & & & & & & \\
\hline $\mathrm{S} 5+700$ & 732.5 & 2.86 & & & & & & & & & \\
\hline$S 1+1000$ & 1400 & 3.15 & 1175 & 3.07 & 3.22 & 3.07 & 0.0000 & 0.0000 & 104.80 & 0.0000 & 0.0000 \\
\hline $\mathrm{S} 2+1000$ & 1400 & 3.15 & 1175 & 3.07 & & & & & & & \\
\hline $\mathrm{S} 3+1000$ & 1400 & 3.15 & & & & & & & & & \\
\hline $\mathrm{S} 4+1000$ & 1450 & 3.16 & & & & & & & & & \\
\hline $\mathrm{S} 5+1000$ & 1400 & 3.15 & & & & & & & & & \\
\hline
\end{tabular}




\section{JURNAL TEKNOLOGI PROSES DAN INOVASI INDUSTRI, VOL. 4, NO. 2, NOVEMBER 2019}

Tabel IV adalah hasil pengolahan data dari hasil pengujian Coliform. Tabel ini menunjukkan bahwa presisi pada kelompok sampel tanpa cemaran, tidak ada bakteri target yang tumbuh, kelompok sampel dengan penambahan cemaran 10 koloni/ml adalah 0.000 , pada kelompok sampel dengan penambahan cemaran $100 \mathrm{koloni} / \mathrm{ml}$ adalah 0.000 , pada kelompok sampel dengan penambahan cemaran $500 \mathrm{koloni} / \mathrm{ml}$ adalah 0.0699 , pada kelompok sampel dengan penambahan cemaran 700 koloni/ml adalah 0.0467 dan pada kelompok sampel dengan penambahan cemaran $1000 \mathrm{koloni} / \mathrm{ml}$ adalah 0.000. Semuanya berada di bawah batas keberterimaannya yaitu $<0.1$, sehingga dapat disimpulkan bahwa presisi hasil pengujian coliform memenuhi batas keberterimaannya.

Tabel IV juga menunjukkan bahwa hasil akurasi pada kelompok sampel dengan penambahan cemaran $10 \mathrm{koloni} / \mathrm{ml}$ adalah $85.03 \%$, kelompok sampel dengan penambahan cemaran 100 koloni/ml adalah 100.85\%, kelompok sampel dengan penambahan cemaran $500 \mathrm{koloni} / \mathrm{ml}$ adalah $99.22 \%$, kelompok sampel dengan penambahan cemaran $700 \mathrm{koloni} / \mathrm{ml}$ adalah $99.41 \%$ dan pada kelompok sampel dengan penambahan cemaran 1000 koloni/ml adalah 104.80\% Semuanya berada dalam rentang keberterimaan akurasi yaitu $85-105 \%$, sehingga dapat disimpulkan bahwa akurasi hasil pengujian coliform memenuhi batas keberterimaannya

TABLE V. LINEARITAS COLIFORM PADA AIR MINERAL

\begin{tabular}{|c|c|c|c|c|c|c|}
\hline Kontrol & 0 & 1.00 & 2.10 & 2.71 & 2.86 & 3.22 \\
\hline $\begin{array}{c}\text { Sampel }+ \\
\text { spike }\end{array}$ & 0 & 1.18 & 2.08 & 2.73 & 2.88 & 3.07 \\
\hline
\end{tabular}

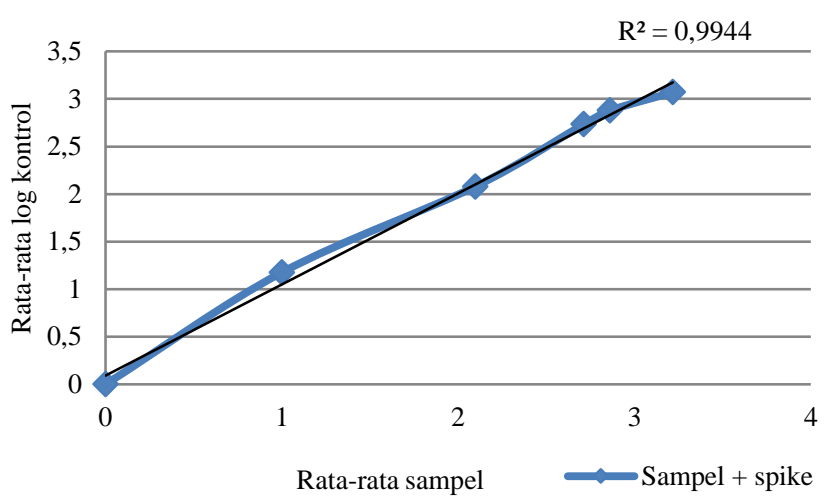

Gambar 5. Kurva Linearitas Air Mineral

Tabel V dan Gambar 5 menunjukkan bahwa linearitas verifikasi metode uji cemaran Coliform adalah sebesar 0.994. Linearitas ini memenuhi syarat keberterimaannya, yaitu $\mathrm{R}^{2}>0,95$.

\section{KESIMPULAN DAN SARAN}

Dari kegiatan Verifikasi metode ini, diperoleh hasil bahwa presisi pada kelompok sampel dengan penambahan cemaran 10 koloni/ml adalah 0.000 , pada kelompok sampel dengan penambahan cemaran $100 \mathrm{koloni} / \mathrm{ml}$ adalah 0.000 , pada kelompok sampel dengan penambahan cemaran $500 \mathrm{koloni} / \mathrm{ml}$ adalah 0.0699, pada kelompok sampel dengan penambahan cemaran $700 \mathrm{koloni} / \mathrm{ml}$ adalah 0.0467 dan pada kelompok sampel dengan penambahan cemaran $1000 \mathrm{koloni} / \mathrm{ml}$ adalah 0.000 . Semuanya berada di bawah batas keberterimaannya yaitu $<0.1$, sehingga dapat disimpulkan bahwa presisi hasil pengujian coliform memenuhi batas keberterimaannya. Hasil akurasi pada kelompok sampel dengan penambahan cemaran $10 \mathrm{koloni} / \mathrm{ml}$ adalah $85.03 \%$, pada kelompok sampel dengan penambahan cemaran $100 \mathrm{koloni} / \mathrm{ml}$ adalah $100.85 \%$, pada kelompok sampel dengan penambahan cemaran $500 \mathrm{koloni} / \mathrm{ml}$ adalah $99.22 \%$, pada kelompok sampel dengan penambahan cemaran 700 koloni/ml adalah $99.41 \%$ dan pada kelompok sampel dengan penambahan cemaran $1000 \mathrm{koloni} / \mathrm{ml}$ adalah $104.80 \%$ Semuanya berada dalam rentang keberterimaan akurasi yaitu 85 - $105 \%$, sehingga dapat disimpulkan bahwa akurasi hasil pengujian coliform memenuhi batas keberterimaannya. Sedangkan untuk linearitas verifikasi metode uji cemaran Coliform adalah sebesar 0.994. Nilai ini memenuhi syarat keberterimaannya, yaitu $\mathrm{R}^{2}>0,95$.

\section{UCAPAN TERIMA KASIH}

Ucapan terimakasih kami tujukan kepada saudara Mya Sukmawati, Sukmawati, Ardhaningtyas Riza Utami dan semua pihak yang telah membantu penulis dalam mengumpulkan data untuk tulisan ini. Selain itu, kami juga mengucapkan terimakasih kepada dewan redaksi majalah sehingga tulisan ini dapat diterbitkan.

\section{DAFTAR PUSTAKA}

[1] Atlas Ronald M, Snyder James W, Handbook of medical for Clinical and Public Health Microbiology. Francis : Crc Press, 2014.

[2] Batt, C. A., Encyclopedia of Food Microbiology.USA: Academic press, Available from : elsevier books. 2014. (diakses pada 6 November 2019)

[3] Eurachem Guide, The Fitness for Purpose of Analytical Methods A Laboratory Guide to Method Validation and Related Topics, Desember 1998

[4] Jawetz., E., Melnick, J.L. and Adelberg, E.A., Mikrobiologi kedokteran. EGC, Jakarta, 2010.

[5] Lynch, J.M., dn N.J. Poole, Microbial ecology:A Conceptual Approach, John Wiley and Sons, New York, 1979

[6] Peraturan Menteri Kesehatan RI No. 492/MENKES/PER/IV/2010 tentang Persyaratan Kualitas Air Minum, 2010

[7] Raugel, P.J., Rapid Food Analysis and Hygiene Monitoring Kits, Instruments and Systems. France, 2012.

[8] SAC-SINGLAS (Singapore Laboratory Accreditation Scheme) Guidance Notes $\mathrm{C} \& \mathrm{~B}$ and ENV 002, Method Validation of Microbiological Methods, 2002

[9] SNI 3553:2015, Air Mineral, Badan Standarisasi Nasional, Jakarta, 2015

[10] SNI 3554:2015, Cara Uji Air Minum dalam Kemasan, Badan Standarisasi Nasional, Jakarta, 2015

[11] SNI ISO IEC 17025: 2017, Persyaratan Umum Kompetensi Laboratorium Pengujian dan Laboratorium Kalibrasi, Badan Standarisasi Nasional, Jakarta, 2017

[12] Sopacua, F.C., Purwijatiningsih, L.M.E., Pranata, S., Kandungan Coliform dan Klorin Es Batu di Yogyakarta, 2013.

[13] Suriaman, E,Juwita, Jurnal penelitian mikrobiologi pangan "Uji Kualitas Air“, Jurusan Biologi Fakultas Sains dan Teknologi Universitas Islam Negeri Malang, 2008. http://www.scribd.com. Diakses pada tanggal 5 November 2019. 